\title{
Free Health Care Policy in Nepal: Recent Trend and Challenges
}

\author{
Gurung $\mathrm{G}^{1}$ \\ 'Save the Children, Baghdarbar, Sundhara, Kathmandu, Nepal
}

\section{ABSTRACT}

The willingness to pay for services can not be equated with ability to pay for it. Despite of Alma-Ata declaration in 1978, developing countries have numerous challenges to meet the goal of health for all. In the quest for increasing access to health for all, Government of Nepal has recently introduced free health care policy. The efficacy of its implementation, operational challenges and issues related to the free health care, need to be reviewed. The unnecessary use of services, quality of care, risk of medicalization of public health services, mismanagement of drugs and health worker resistance towards the policy are some of its key challenges. To overcome these, community awareness and participation to monitor implementation of the policy is necessary and long term efficacy of this service has yet to be observed.

Key words: community monitoring system, free health care policy, participation

\section{INTRODUCTION}

The Alma-Ata declaration is promoting health for all. ${ }^{1}$ However, 30 years after its declaration the underutilization of health services especially by poor and marginalized has become a big problem in developing countries like Nepal. ${ }^{2}$ In our context, financial aspect has become an important barrier for the accessibility to health for all. ${ }^{3}$ The willingness to pay for the services can not be equated with ability to pay for it. The issue of health for all is a challenge for developing countries like ours e.g. in Tanzania, public hospital saw attendance drop by $53 \%$ when user fee was introduced. In contrast, poor are mostly benefitted from this services where national policies includes universalism. ${ }^{1}$ Evidence from other low-income countries showed that provision of free health service increases its use. ${ }^{4}$ In a bold move to increase access to health services and promote equity and the fundamental rights of citizens, government of Nepal (GON) has recently introduced free basic health care for all. ${ }^{5}$ Even though a popular policy based on socialist ideology and politically influenced ${ }^{6}$ there are many challenges yet to be solved. The effective implementation of the policy and its vision of health for all, we need to sort out these issues and challenges and make appropriate strategies to deal with it. Some of the important issue that has been highlighted, if addressed can help long term sustainability of this service in our country.

\section{Unnecessary use of Services}

When free health care policy is introduced, cost to users falls to zero. It might increases the tendency of unnecessary and over utilization of health care. ${ }^{2}$ It would result in increase in demand of health care unnecessarily with decreasing quality of care and increasing cost of care. Therefore, a clear policy, increment in the infrastructure and human resource management would be of outmost important before widespread implementation of this program. 
Free Health Care Policy in Nepal: Recent Trend and Challenges

\section{Quality of Care}

As a result of free health care service there will be increase in demands in health services. Ultimately, the quality of care in health facilities is likely to suffer due to inadequate staffing and infrastructure, inadequate supply of drugs, and decrease in average time for consultations. A constant monitoring and implementation of effective measure would help to overcome such issues.

\section{Risk of Medicalization}

In general, people give more value to curative care in comparison to preventive care. The increase client flow in health facilities towards the free health care services might be due to the increased demand in curative services. It would lead to absorption of resource allocated to free health care services by curative care resulting in budget cutback in high priority public health program. This in turn increases the risk of medicalization of public health services by unnecessary demand of curative care. The popular belief of prevention is better than cure has to be addressed.

\section{Free is not Really Free}

There is no free bread in this world. Similarly, the free health care is not really free. There are many other institutional barriers including cost of transportation, management and services. On the top of that, the poor and marginalized people have hand to mouth problem for their livelihood. In this scenario these people many not come for the services. These barriers are probably the main reasons why even after health care is made free, has not reached to these group. ${ }^{3}$ It is necessary for health system to address those barriers to ensure free health for all in Nepal.

\section{Exclusion of Poor and Marginalized}

It is important that poor and excluded constitute the majority of those who would be benefited from this policy. However, due to lack of proper monitoring, this group has been left aside. The people in the urban areas are more aware and most of these services are located in these areas only. But, we need to have awareness program and infrastructure development in the poor and marginalized community for their access to health. Proper community monitoring system should be established to ensure the inclusion of poor and excluded in free health care services.

\section{Mismanagement of Free Drugs}

The mismanagement of free drugs and supply become a head line of newspapers in Nepal. It ranged from the sale of free drug in private medical shop to wastage of drugs in store/health facility. Similarly, distribution of drugs has to be according to the disease patter of that locality. There has been report of shortage of certain drugs whereas few of them have not been used once. We need to have a monitoring, evaluation and scientific distribution of free drugs according to the region specified in our context.

\section{Health worker resistance}

There are chances of resistance from health care providers towards free health care. It is because the demand for free service is equally proportional to increase in increases work load at public health institutions. ${ }^{2}$ We need to increase human resource, and infrastructure to deal with this issue. Our country has not increased its human resource and infrastructure since 1990 when the population was merely 15 million. In the scenario of our current population of 27 million, free health service with the same manpower and infrastructure laid down in 18 years ago would not provide effective services at the moment. This situation may lead to the resistance from health workers in long run.

Even though, free health care policy has many challenges, if properly implemented and monitored, it promotes equity in health sector and contributes to achieve vision of health for all. Although, it was a political decision without proper homework, we need to address all those challenges for its long term sustainability. If we fail to do so, this free health service in Nepal would be limited to words only.

\section{REFERENCES}

1. World Health Organization. Declaration of Alma-Ata [Online]. [cited 2008 Aug 10]; Available from: URL:www.who.int/hpr/ $\mathrm{NPH} /$ docs/declaration_almaata.pdf

2. RTI International. Implications of the Government of Nepal's free health care policy. Kathmadu: Health Sector Reform Support Program; 2007.

3. Mamdani B. Alternatives to user fees for public health care. Indian J Med Ethics. 2007;4:138-40.

4. Oxfam. Government of Nepal scraps user fees for basic health care [Online]. 2008 [cited 2009 Feb 2]; Available from: URL:http:/ / www.oxfam.org.uk/applications/blogs/policy/2008/01

5. Department of Health Services. Annual report, 2006/2007. Kathmandu: Department of Health Services; 2007.

6. Indira Gandhi National Open University. Health in rural India. New Delhi: Young Printing Press; 2001. 